University of Warwick institutional repository: http://go.warwick.ac.uk/wrap This paper is made available online in accordance with publisher policies. Please scroll down to view the document itself. Please refer to the repository record for this item and our policy information available from the repository home page for further information.

To see the final version of this paper please visit the publisher's website. Access to the published version may require a subscription.

Author(s): JON BROCK, CAROLINE C. BROWN, JILL BOUCHER and GINA RIPPON

Article Title: The temporal binding deficit hypothesis of autism

Year of publication: 2002

Link to published

version: http://dx.doi.org/10.1017/S0954579402002018

Publisher statement: None 


\title{
The temporal binding deficit hypothesis of autism
}

\author{
JON BROCK,${ }^{a}$ CAROLINE C. BROWN,${ }^{a}$ JILL BOUCHER,${ }^{a}$ AND \\ GINA RIPPON ${ }^{b}$ \\ ${ }^{a}$ University of Warwick, UK; and ${ }^{b}$ University of Aston, $U K$
}

\begin{abstract}
Frith has argued that people with autism show "weak central coherence," an unusual bias toward piecemeal rather than configurational processing and a reduction in the normal tendency to process information in context. However, the precise cognitive and neurological mechanisms underlying weak central coherence are still unknown. We propose the hypothesis that the features of autism associated with weak central coherence result from a reduction in the integration of specialized local neural networks in the brain caused by a deficit in temporal binding. The visuoperceptual anomalies associated with weak central coherence may be attributed to a reduction in synchronization of high-frequency gamma activity between local networks processing local features. The failure to utilize context in language processing in autism can be explained in similar terms. Temporal binding deficits could also contribute to executive dysfunction in autism and to some of the deficits in socialization and communication.
\end{abstract}

Autism is a developmental disorder that is currently defined in terms of a triad of impairments in social interaction, communication, and behavioral flexibility (American Psychiatric Association, 1994; World Health Organization, 1992). Autism is also associated with certain perceptual and attentional abnormalities and is commonly but not universally associated with mental retardation (e.g., Wing, 1996). Numerous theories have been proposed regarding the cognitive and neurological causes of these behavioral features (see Bailey, Phillips, \& Rutter, 1996, for a review). At the cognitive level, most current theories address either the impairments in social interaction and communication (e.g., BaronCohen, 1995; Hobson, 1993; Meltzoff \& Gopnik, 1994; Mundy \& Sigman, 1989; Rogers \& Pennington, 1991) or the behavioral inflexi-

We thank Chris Jarrold, Kit Pleydell-Pearce, and Hans van Dalen for comments on an earlier draft of this paper.

Address correspondence and reprint requests to: Jon Brock, Department of Psychology, University of Warwick, Coventry, CV4 7AL, UK; e-mail: j.p.brock@ warwick.ac.uk. bility (e.g., Damasio \& Maurer, 1978; Harris, 1993; Ozonoff, 1995; Pennington, 1994). The focus of this paper, however, is on the perceptual and attentional abnormalities that these theories do not specifically address.

Frith (1989) suggested that many of the perceptual and attentional abnormalities in autism could be interpreted in terms of a reduction in the contextual integration of information and a bias toward local rather than global processing, which she termed weak central coherence. This account is supported by a large body of research, but a number of negative findings exist (Happé, 1999). Moreover, the account can be criticized as being descriptive rather than explanatory and, related to this, the underlying cognitive and neural mechanisms of weak central coherence are not addressed. In this paper we address these issues by linking the weak central coherence account with recent research into the integration of neural activity through temporal binding. This allows us to explain some experimental findings that have proved difficult for the weak central coherence account and to generate testable hypotheses. 
The plan of this paper is as follows: we begin by reviewing the weak central coherence account and the evidence for and against it. Next we suggest that weak central coherence is the result of a failure to integrate information from different specialized local networks in the brain and argue that this impairment will become increasingly important as the developing brain becomes more specialized. After reviewing the mechanisms proposed for brain integration, we propose the hypothesis that weak central coherence is associated with impairment of temporal binding between local networks and compare this hypothesis to recent models of autism based on artificial neural networks. Next, we relate weak central coherence in visual perception and language processing to recent studies of high-frequency gamma electroencephalogram (EEG) activity and make some specific predictions regarding the outcomes of potential EEG studies of autism. In the final section we return to the defining triad of impairments and suggest that impaired temporal binding could play a contributory role in the behavioral inflexibility and social and communication aspects of the disorder.

\section{The Weak Central Coherence Theory of Autism}

Central coherence is defined as "the everyday tendency to process incoming information in its context-that is, pulling information together for higher level meaning, often at the expense of memory for detail" (Happé, 1999, p. 217). Frith and Happé (Frith, 1989; Frith \& Happé, 1994; Happé, 1999) describe people with autism as having weak central coherence in that they "show detail-focused processing in which features are perceived and retained at the expense of global configuration and contextualised meaning" (Happé, 1999, p. 217).

This account is supported by studies that show that people with autism have a local bias in visual perception and visuospatial construction: they perform relatively well on tasks that require them to process the constituent parts of objects or scenes but perform poorly when required to process the whole object or scene
(Happé, 1999). Thus, individuals with autism perform better than controls on the embedded figures task in which a hidden shape has to be found in a larger picture (Jolliffe \& BaronCohen, 1997; Shah \& Frith, 1983). They also perform better than controls on the block design task in which a pattern has to be constructed from painted blocks (Shah \& Frith, 1993). When the pattern is presegmented, controls perform as well as individuals with autism, suggesting that the autistic individuals' superior performance in the unsegmented condition is associated with unusual facility in breaking down the original pattern. Several studies show that children with autism process faces feature by feature (Davies, Bishop, Manstead, \& Tantam, 1994; Langdell, 1978; Miyashita, 1988; Tantam, Monaghan, Nicholson, \& Stirling, 1989) rather than by using the holistic and configurational encoding strategies that are used by typically developing children from the age of about 7 years (e.g., Carey \& Diamond, 1977). A local bias also seems to be reflected in the detail by detail drawing style adopted by savant artists with autism (Mottron \& Belleville, 1993) and in the anomalous ability of people with autism to copy impossible figures (Mottron, Belleville, \& Ménard, 1999). Finally, Happé (1996) reported that children with autism were relatively immune to certain visual illusions, a finding she interpreted in terms of local processing.

A local bias in visual perception is also consistent with first-hand accounts given by some able people with autism. For example, van Dalen (1994) writes:

I have discovered during the years that my way of perceiving things differs from that of other people. For instance, when I am confronted with a hammer I am initially not confronted with a hammer at all but solely with a number of unrelated parts: I notice a cubical piece of iron with in its neighborhood a coincidental bar-like piece of wood. After that I am struck by the coincidental nature of the iron and the wooden thing resulting in the unifying perception of a hammer-like configuration. The name "hammer" is not immediately within reach but appears when the configuration has been sufficiently stabilized over time. Finally, the use of a tool becomes clear when I realize that this percep- 
tual configuration, known as a "hammer," can be used to do carpenter's work.

Further evidence for weak central coherence in autism comes from studies of language processing, which show that individuals with autism are unimpaired when processing the meaning of individual words (Eskes, Bryson, \& McCormick, 1990; Frith \& Snowling, 1983) but have difficulty integrating the meaning of different words in a sentence. A well-replicated finding is that people with autism fail to use the context provided by a sentence to find the correct pronunciation of a homograph, for instance, in the sentence, "In her eye was a large tear," compared with, "In her dress was a large tear" (Frith \& Snowling, 1983; Happé, 1997; Snowling \& Frith, 1986). Similarly, they have difficulty using context to interpret ambiguous sentences (Jolliffe \& Baron-Cohen, 1999) and to decide whether questions require direct or indirect responses (Ozonoff \& Miller, 1996).

However, a number of studies have failed to support the weak central coherence account, particularly regarding the claim that individuals with autism show a local bias in visual perception. Brian and Bryson (1996) failed to find superior performance on embedded figures tasks, although this study has been criticized on methodological grounds (Jolliffe \& Baron-Cohen, 1997). Ropar and Mitchell (1999, 2001) found that children with autism were susceptible to certain visual illusions, contrary to earlier claims by Happé (1996).

Particularly difficult for the weak central coherence account are a number of studies utilizing the Navon hierarchical figures paradigm in which participants process either the local or global level of a figure (Navon, 1977). Although one study (Rinehart, Bradshaw, Moss, Brereton, \& Tonge, 2000) has found that individuals with autism show an unusual local interference effect, two other studies (Mottron, Burack, Stauder, \& Robaey, 1999; Ozonoff, Strayer, McMahon, \& Filloux, 1994) have failed to find any evidence for the local bias predicted by weak central coherence. Some of these inconsistencies may be attributed to the differences in the experimental and control groups tested in the various studies or to differences in the absolute and relative sizes of the local and global figures used (see Love, Rouder, \& Wisniewiski, 1999). Plaisted, Swettenham, and Rees (1999) avoided these difficulties by testing the same groups of children on two tasks using similar stimuli. When required to attend to both levels, the children with autism showed an unusual advantage for processing the local level, as predicted by weak central coherence. However, when participants were instructed to which level to attend, the autistic and the control groups both showed a global advantage. This second result presents a substantial difficulty for the weak central coherence account.

These negative findings suggest that there is a need for a more precise definition of weak central coherence and for a more precise formulation of the account in terms of underlying cognitive and neurological deficits. In the remainder of this paper we attempt to address these difficulties by arguing that the findings taken as evidence of weak central coherence in autism (and also the contrary evidence) may be better understood in terms of impaired neural integration. However, we will first suggest in broad terms how neural integration may relate to central coherence and how it may play a crucial role in normal and atypical cognitive development.

\section{Neural Integration and Cognitive Development in Autism}

Information processing in the adult brain occurs in separate specialized functional areas. Converging evidence for this comes from highly specific cognitive deficits found in some neuropsychological patients with localized lesions and from neuroimaging studies that show that different tasks involve the activation of different cortical and subcortical regions. However, these specialized networks do not work in isolation. Rather, the performance of any task is associated with the coactivation of multiple cortical and subcortical regions and successful task performance is dependent on the effective integration of neural output from the distinct brain regions in- 
volved (see, e.g., Tononi, Edelman, \& Sporns, 1998). Central coherence by definition requires the integration of information to achieve "higher level meaning" (Frith, 1989; Happé, 1999). The hypothesis we therefore propose is that the process underlying neural integration is impaired in autism, leading to the deficits associated with weak central coherence.

We further suggest that processes of integration are critical for normal neural and cognitive development and, consequently, that impaired integration will have important implications for the development of autism. The neonate brain, with the exception of some specialized or "hard-wired" connections, is relatively undifferentiated and functional areas become progressively more specialized with development (see, e.g., Elman, Bates, Johnson, Karmiloff-Smith, Parisi, \& Plunkett, 1996; O’Leary, 1989). Several authors have considered the role of specialization processes in normal and abnormal cognitive development (e.g., Johnson, 1999; Oliver, Johnson, Karmiloff-Smith, \& Pennington, 2000), but little consideration has been given to the role of integration mechanisms. We suggest that normal neural and cognitive development requires a delicate balance between specialization and integration. In the unspecialized brain, a particular area will be involved in performing many different tasks and integration between areas will be relatively unimportant. However, as specialization proceeds, there will be an increasing need to integrate information between specialized functional regions.

Our hypothesis can therefore be rephrased in developmental terms as follows: whereas typical brain development involves the emergence of functionally specialized but nevertheless integrated regions, brain development in autism involves the emergence of functionally specialized brain regions that become increasingly isolated from each other over time. Consequently, there will be impaired development of cognitive faculties that require the integrated action of numerous brain regions. In contrast, the development of abilities that rely on relatively localized neural activity should proceed as normal.
In addition to developmental changes, we suggest that there are also differences between individuals with autism in the extent of their integration deficit. In low-functioning individuals the deficit will be pervasive, affecting integration even between proximal brain regions. Thus, for example, impaired integration between different regions of the visual cortex will result in the visuoperceptual abnormalities associated with weak central coherence. However, in higher functioning individuals, such as those diagnosed with Asperger syndrome, integration between such proximal brain regions may be relatively spared, so there will be less evidence of weak central coherence in visuoperceptual processing (cf. Ropar \& Mitchell, 2001). Nevertheless, there will still be deficits in integration between disparate brain regions, so these individuals will still be impaired on higher level cognitive tasks such as the homographs task reviewed above and, more generally, in tasks involving complex information processing (cf. Minshew, Goldstein, \& Siegel, 1997) and the coordinated action of multiple brain regions (Tononi, Edelman, \& Sporns, 1998).

If this hypothesis is to advance our understanding of autism it is of crucial importance to identify the specific mechanisms involved so that the hypothesis may be tested empirically. The question of exactly how different brain regions interact and consequently how information is integrated in the brain has become known as the binding problem. In the following section, we review two proposed solutions to the binding problem: combination coding and temporal binding. We then suggest that it is the temporal binding mechanism that is impaired in autism and that this impairment leads to the features of autism associated with weak central coherence.

\section{Solutions to the Binding Problem}

The binding problem is illustrated by a classic example provided by Rosenblatt (1961; see Figure 1), in which a simple neural network is presented with a triangle or a square that can be in either the top or the bottom of a display. The network has four output neurons that fire to represent square, triangle, top, and 

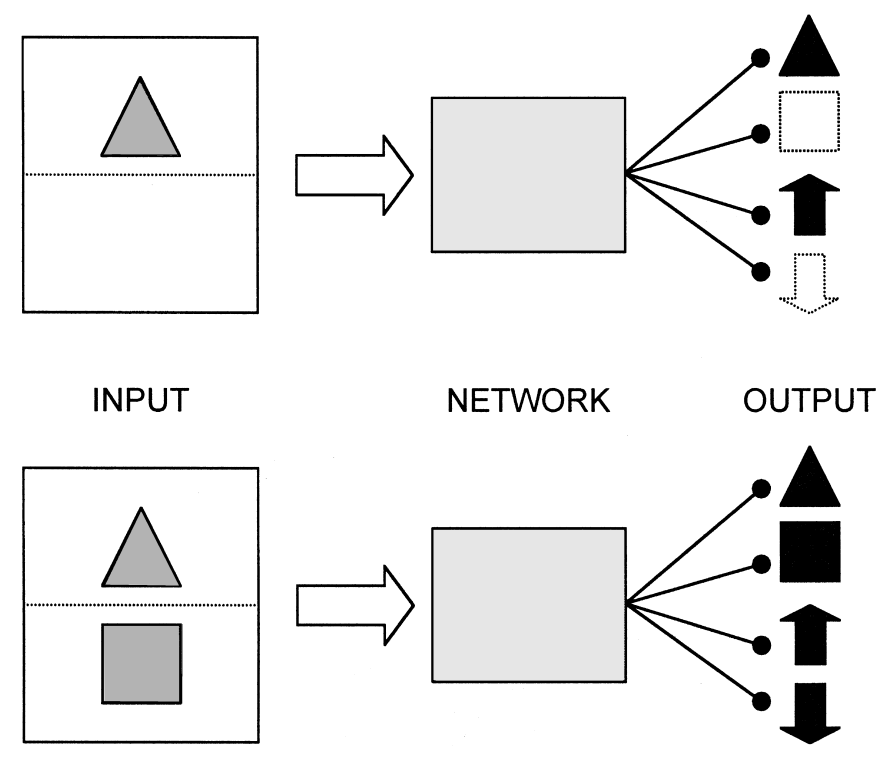

Figure 1. Rosenblatt's illustration of the binding problem.

bottom and can therefore represent a single object and its location by the firing of two neurons. In the first example in Figure 1 a triangle at the top is represented by the output triangle, top. However, in the second example both objects are presented simultaneously and the output reads triangle, square, top, bottom, so it is impossible to determine which shape is in which location.

The combination coding solution to this problem was first proposed by Barlow (1972). This solution involves an additional four neurons that each respond to one of the four possible combinations of shape and position. One neuron would, for example, respond selectively to a triangle at the top, another to a square at the bottom. Ghose and Maunsell (1999) suggest that combination coding alone is sufficient to solve the binding problem, and Riesenhuber and Poggio (1999) recently provided a neural network model based on the combination coding solution. Moreover, there is evidence that combination coding does occur in early visual processing (Hubel \& Weisel, 1977, 1979), although it has not been found in relation to other higher cognitive processes. However, other researchers argue that it is unlikely that combination coding provides a complete solution to the binding problem (see, e.g., Engel, König, Kreiter,
Schillen, \& Singer, 1992; Gray, 1999; Singer, 1999a, 1999b; Treisman, 1998, 1999; von der Malsburg, 1999). One objection is that there are not enough cells in the brain to code for every possible combination of features. This may be countered by arguing that only important combinations are encoded, but this in turn leads to problems in explaining the perception of novel objects: "A purple giraffe with wings would look surprising but it would not be invisible" (Treisman, 1998, p. 1296). Combination coding also fails to account for hierarchical representations because cells would be required to code the pathways activated at each level of the hierarchy, and these would presumably still require binding.

The temporal binding solution to the Rosenblatt problem was first advocated by Milner (1974) and then by von der Malsburg (1981). They argued that combinations of features (i.e., shape and position) could be represented by the synchronous firing of neurons responding to the different dimensions of a particular object. So, in the second example in Figure 1 the triangle and top neurons would be active simultaneously but fire at a different time than the square and bottom neurons. More generally, neurons responding to the same object could be tagged by temporal correlation of their firing patterns (Singer, 
Engel, Kreiter, Munk, Neuenschwander, \& Roelfsema, 1997). ${ }^{1}$

The position currently advocated by, for example, Gray (1999), Singer (1999a, 1999b), and von der Malsburg (1999) is that combination coding provides a partial solution to the binding problem but temporal binding is required to "step in" whenever combination coding is not an option. According to this view, combination-coding is involved in the representation of well-learned information whereas temporal binding is responsible for the flexible integration of information, allowing the perception and representation of novel objects and environments. Temporal binding also allows the integration of information at different levels of processing, thus permitting hierarchically organized representations.

\section{The Temporal Binding Deficit Hypothesis of Autism}

The hypothesis we present here is that the features of autism associated with weak central coherence are the result of impaired temporal binding. ${ }^{2}$ Such an impairment would force the individual with autism to rely heavily on combination coding. This would lead to difficulties in the automatic and flexible integration of information, with the representation of novel objects and situations, and with the hierarchical representation of whole objects as collections of parts.

However, we do need to be careful when specifying the exact nature of the proposed temporal binding deficit in autism. Earlier we argued that weak central coherence resulted from impairment of the integration of information between specialized brain regions. Within these regions populations of neighboring neurons that are each coarsely tuned to several different dimensions must be bound

1. Neurons are continually active; they raise and reduce their rate of activity around their baseline value. If two or more increase their activity to the same rate simultaneously, their output is correlated over time.

2. Frith (1997) and Fost (1999) have briefly speculated that there may be some form of impairment to the temporal binding mechanism in autism, although neither author has expanded on this suggestion. together to represent positions on particular feature dimensions (Singer, 1999b). Thus, a deficit in temporal binding at this local level would lead to problems with the representation of simple feature dimensions and there is no indication that people with autism have such difficulties. Consequently, we suggest that it is the impairment of temporal binding between local networks that results in the deficits found in autism whereas temporal binding mechanisms within local networks are intact or possibly even enhanced.

Anatomical distinctions between local and global networks in the cortex are well established (Braitenberg, 1978; Bressler, 1996). This distinction is also crucial to a number of models of cortical activity based on results from EEG studies. For example, Nunez $(1998,2000)$ has defined a testable model of the interaction between local and global fields of cortical "synaptic action" (i.e., the number of active synapses per unit volume). He suggests that the combined activity of a large number of local networks forms a pattern of global synaptic action or "global field activity." Individual local networks can drive modulations in the global activity, and at the same time global activity exerts a top-down effect on local activity. Two independent local networks can thus become temporally correlated indirectly via the global activity.

Although he does not specifically relate his model to autism, Nunez (2000) predicts the possibility of pathological conditions giving rise to states of so-called hypocoupling, whereby global field activity has little influence on local cortical networks. This situation entails that local networks do not become temporally correlated with one another and therefore process information in relative isolation. Weak central coherence could therefore be conceived as the cognitive manifestation of the hypocoupling of local neural networks. Nunez suggests that hypocoupling could arise because of neurotransmitter imbalance or a reduction in long-range connections in the cortex. His model therefore provides a potential link between cognitive deficits and underlying structural or neurochemical abnormalities in autism.

A similar dynamic local-global network 
model was earlier proposed by Thatcher, Krause, and Hrybyk (1986) and applied to EEG data from children. It was found that levels of EEG coherence between different cortical sites in children increase and decrease in cycles with periods of between 2 and 4 years (Thatcher, 1992, 1994a). Thatcher (1994b) argued that each cycle reflects an increase in the number and/or strength of synapses followed by a period of synaptic pruning and that these cycles result in stepwise increases of differentiation and integration. This argument is consistent with our earlier suggestion that normal cognitive development relies on mechanisms of specialization and integration. The temporal binding deficit hypothesis predicts that if a similar study was carried out with children with autism, these cycles would be found to be disturbed. More specifically, if reduced integration results from limited growth of longrange connections, then it is likely that a reduction in the extent or duration of the periods of increased coherence would ensue. Alternatively, excessive pruning of these connections would result in attenuated coherence. Such a study would help identify the underlying neurodevelopmental causes of reduced integration in autism.

\section{Neural Net Models of Autism}

The temporal binding deficit hypothesis is not the first to suggest that diffuse abnormalities of brain organization have a causative role in autism. Cohen (1994) and McClelland (2000) proposed models of autism based on the principles of traditional feedforward artificial neural networks. Cohen suggested that certain regions of the autistic brain have either too few or too many processing units, and McClelland proposed that the brains of individuals with autism are predisposed to an excessively conjunctive form of neural coding, implying an unusual degree of reliance on combinatorial coding. Gustafsson (1997), on the other hand, based his model of autism on the model of cortical function proposed by Kohonen (1984, $1995)$ in which neurons are arranged in columns so that nearby columns are activated by objects with similar features. Gustafsson suggested that excessive inhibitory feedback in autism leads to an arrangement of feature maps in which these columns are too narrow.

All three neural net models predict that people with autism will tend to treat similar stimuli as completely different. They could therefore explain the enhanced discrimination abilities shown by individuals with autism in visual search (O'Riordan, 2000; O'Riordan, Plaisted, Driver, \& Baron-Cohen, 2001; Plaisted, O'Riordan, \& Baron-Cohen, 1998b) and perceptual learning tasks (Plaisted, O'Riordan, \& Baron-Cohen, 1998a). The models could also explain the impaired generalization found in studies looking at categorization abilities in autism (Klinger \& Dawson, in press; Plaisted, 2000; but see Bott, Brockdorff, Brock, Boucher, \& Lamberts, 2002; Molesworth, Bowler, \& Hampton, 2002).

These neural network models of autism offer explanations of processing within local networks in autism that are descriptively compatible with our own hypothesis. However, they are not directly testable at the neurobiological level. In contrast, the temporal binding deficit hypothesis is directly testable using EEG. Specifically, it should be possible to find evidence of hypocoupling (as described by Nunez, 2000, see above) in the EEGs of individuals with autism. In the next section, we review studies linking temporally correlated EEG activity in the gamma frequency band $(30-100 \mathrm{~Hz})$ with the visual perception of coherent objects. We then make specific predictions about the outcomes of similar studies with people with autism.

\section{Perceptual Coherence and Gamma Band EEG Activity}

An EEG electrode measures the combined electrical activity of a large number of neurons underlying the region of the scalp where it is placed. The resultant signal can be decomposed into its constituent frequencies that can then be analyzed separately. Oscillatory activity indicates that neurons within a local group are firing in near synchrony. If oscillatory activity between two distant electrodes is correlated, this indicates that distant local groups are working together, and can be mathematically tested for "coherence" (Shaw, 
1981, 1984). The human EEG shows oscillatory activity across a wide range of frequency bands, each of which may have its own functional significance (e.g., Basar, 1999; Basar, Basar-Eroglu, Karakas, \& Schürmann, 2000, 2001). In recent years the research has concentrated on temporal correlation of activity in the high-frequency gamma band and its relation to visual perception. This research gives us an opportunity to make direct links between EEG studies of visual perception and weak visuoperceptual coherence in autism.

EEG studies have shown that the perception of coherent objects is associated with increased gamma activity over visual areas (Gruber, Müller, Keil, \& Elbert, 1999a; Müller, Bosch, Elbert, Kreiter, Sosa, Sosa, \& Rockstroh, 1996; Müller, Junghofer, Elbert, \& Rockstroh, 1997; Tallon-Baudry, Bertrand, Delpeuch, \& Pernier, 1996; see TallonBaudry \& Bertrand, 1999, for review). The typical paradigm employed in these studies required the participant to process visual stimuli that gave rise to the perception of coherent visual objects and control stimuli that did not. Figure 2 shows an illusory Kanisza triangle and a control figure that does not produce an illusory shape. Tallon-Baudry et al. (1996) reported increases in gamma activity overlying visual regions (occipital and parietooccipital) during the perception of illusionary triangles compared with the viewing of control figures. However, their analyses focused only on groups of electrodes located over visual regions and did not provide a direct test of whether gamma activity recorded at different sites was temporally correlated.

To date, the only reported study that has directly tested the temporal correlation (phase synchrony) of distant cortical gamma activity is that of Rodriguez, George, Lachaux, Martinerie, Renault, and Varela (1999). Figure 3 shows an upside-down Mooney figure that, when rotated through 180 degrees, can be perceived as a face in shadow. Rodriguez et al. presented similar stimuli and found a long-distance pattern of synchronization (i.e., between frontal and occipitoparietal channels) within the gamma band frequency when faces were perceived.

These results suggest that local groups of cells representing individual features are

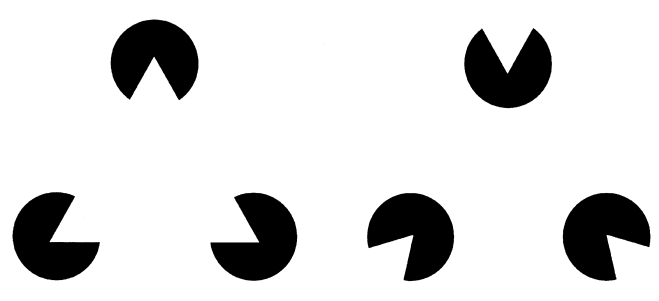

Figure 2. An illusory Kanizsa triangle and a control figure.

bound together into a larger global group by their synchronous firing, leading to the representation of the whole object. If people with autism tend to see objects as a collection of parts rather than as a whole, this would suggest that in autism the local groups of cells representing features are not bound together to the extent that they are in the typical brain. This account is consistent with the kind of difficulty experienced in integrating the object parts into wholes described by van Dalen (1994), who was quoted above. It also provides a means of understanding the unusual success of individuals with autism on tasks such as the embedded figures task (Jolliffe \& Baron-Cohen, 1997; Shah \& Frith, 1983) in which they are required to detect a shape hidden in a larger display. We suggest that this task is difficult for most nonautistic people because the cells representing the shape are automatically recruited into the larger wholeobject representation. However, a deficit in temporal binding would make this automatic recruitment process less effective and detecting the hidden shape would become correspondingly easier.

This account could also provide a potential explanation for some of the findings that the weak central coherence account cannot explain. Plaisted et al. (1999) used the Navon hierarchical figures paradigm and found that children with autism, like controls, showed a global advantage when instructed to which level of the figure to attend. However, the autism group showed an unusual local advantage when required to divide their attention between both levels. Plaisted et al. suggested that their results could be explained by a combination of two factors. The first is en- 


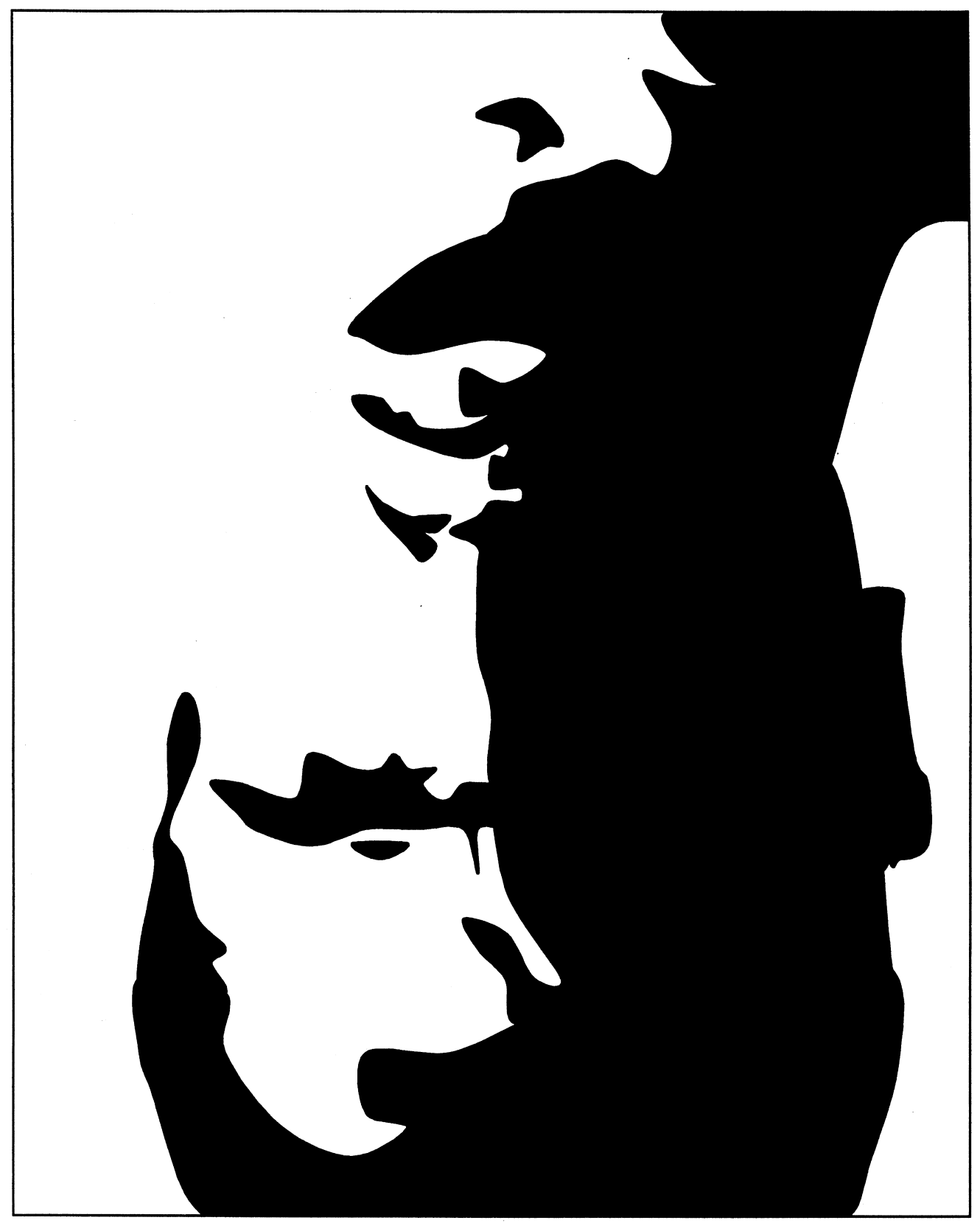

Figure 3. An upside-down Mooney face. When rotated through 180 degrees, a face can be seen.

hanced processing of local features or an inability to filter out information in the absence of explicit instruction to attend to a particular level. According to our hypothesis, this results from the failure of the binding together of local features. The second factor is a difficulty in voluntarily switching attention between the two levels. This can also be interpreted in terms of a temporal binding deficit. Electrophysiological measures of visual attention switching have shown increased activity over both frontal and visual areas (Hillyard \& Anllo-Vento, 1998; Smith \& Jonides, 1999). Visuospatial attention is also associated with 
increased levels of frontal gamma activity (Brown, 2001; Gruber, Müller, Keil, \& Elbert, 1999b), implying that frontal gamma activity modulates activity in the visual cortex. A reduction in binding of gamma activity between the frontal and visual cortex would therefore lead to the deficits in voluntary attention switching reported in autism (e.g., Minshew, Luna, \& Sweeney, 1999).

The hypothesis also allows us to make specific predictions regarding the outcome of EEG studies of perceptual binding in autism using paradigms such as those employed by Rodriguez et al. (1999) and Tallon-Baudry et al. (1996). When people with autism view globally coherent stimuli, we might expect to find an appropriate increase in gamma activity overlying visual areas, reflecting the operation of local networks that are processing local features. However, we would predict an absence or reduction of correlated gamma activity between electrode sites overlying frontal and visual regions that reflects a reduction in the global temporal binding mechanism.

\section{Central Coherence in Language Processing}

The temporal binding deficit hypothesis could also provide an explanation for the reduced influence of context in language processing, as evidenced by the poor performance of people with autism on the homographs test (Frith \& Snowling, 1983; Happé, 1997; Snowling \& Frith, 1986) and their difficulties in interpreting ambiguous sentences (Jolliffe \& Baron-Cohen, 1999). Pulvermüller and colleagues have shown that processing of individual words is associated with increased gamma EEG activity, compared with processing of nonwords (Pulvermüller, Lutzenberger, Preissl, \& Birbaumer, 1995). Moreover, the location of this activity depends on the semantic nature of the words: concrete nouns are associated with enhanced gamma activity over the visual and visual association cortex whereas action verbs lead to increased activity overlying the motor cortex (Pulvermüller, Preissl, Lutzenberger, \& Birbaumer, 1996). An analogy with visual processing would sug- gest that gamma activity corresponding to words processed in different local regions must be bound together into a coherent global pattern to represent the meaning of the sentence. A deficit in this binding process would lead to individual words being processed out of context. However, processing the meaning of individual words would be unimpaired (Eskes et al., 1990; Frith \& Snowling, 1983) because it involves local activity and welllearned associations between semantic and phonological representations.

Braeutigam, Bailey, and Swithenby (2001) have recently reported a study in which participants were presented with sentences whereby the final word was either congruent or incongruent (e.g., "To keep warm, Mark wore a scarf and a furry hat/glass"). Phaselocked gamma band EEG activity was identified at around 300 and $500 \mathrm{~ms}$ after presentation of the final word and was found to be dependent on the congruence of the sentence, being increased in the incongruent condition. Given the similarities between this paradigm and the homographs task, we would expect to find a reduced influence of semantic congruence on this gamma activity in autism.

Similar paradigms have been utilized to investigate the influence of context in sentence processing with event-related potentials (ERPs), which measure the change in the EEG waveform following an event such as the presentation of a target word. These studies have identified a negative peak in the ERP approximately $400 \mathrm{~ms}$ after stimulus onset (the N400) that is larger when the target word is semantically incongruous than when the target word is congruous with the semantic context (e.g., Connolly, Phillips, \& Forbes, 1995; Kutas \& Hillyard, 1980; see Kutas \& Federmeier, 2000, for a review). Consistent with our account, Dunn, Vaughan, Kreuzer, and Kurtzberg (1999) have reported that the N400 in autism is not influenced by semantic congruence in a word categorization task.

\section{Temporal Binding and the Triad of Impairments}

In this paper we have taken the weak central coherence account of autism as a starting 
point in an attempt to link some of the cognitive and behavioral features of autism with potential underlying neural anomalies. However, this account is rather limited in scope because it does not specifically address the triad of impairments in social interaction, communication, and behavioral flexibility that provide the defining features of autism. In this section we briefly consider the role that a temporal binding deficit might have as a contributory cause of these impairments.

Behavioral inflexibility in autism is commonly attributed to impaired executive functions (Damasio \& Maurer, 1978; Harris, 1993; Ozonoff, 1995; Pennington, 1994). Numerous studies have shown that people with autism perform poorly on tests of executive function (McEvoy, Rogers, \& Pennington, 1993; Ozonoff, Pennington, \& Rogers, 1991; Prior \& Hoffmann, 1990; Rumsey \& Hamburger, 1988) and, in particular, on tasks requiring attentional set shifting (Ciesielski \& Harris, 1997; Hughes, Russell, \& Robbins, 1994; Ozonoff, 1997; Ozonoff \& Jensen, 1999). We suggest that attentional set shifting relies on the modulating influence of frontal networks on other task-relevant brain regions. A reduction in binding between frontal and relevant posterior networks would consequently reduce the executive control of frontal regions leading to impaired attentional set shifting. This hypothesis is testable. Increased gamma EEG activity is commonly associated with attentional processes (Brown, 2001; Gruber et al., 1999b; Steinmetz, Roy, Fitzgerald, Hsiao, Johnson, \& Niebur, 2000; Tiitinen, Sinkkonen, Reinikainen, Alho, Lavikainen, \& Näätänen, 1993), so we would predict that, compared with controls, individuals with autism would show a reduction in the temporal correlation of gamma EEG activity between electrodes overlying frontal and posterior regions when required to switch attentional set.

Impaired temporal binding might also contribute to the social and communication deficits in autism. One explanation of these deficits is in terms of impaired theory of mind (the ability to interpret behavior in terms of underlying mental states; see, e.g., Baron-Cohen, TagerFlusberg, \& Cohen, 2000). Frith (1989) sug- gested that theory of mind relies heavily on the ability to integrate multiple sources of social information and that its impairment could therefore be accounted for in terms of weak central coherence. In support of this view, Jarrold, Butler, Cottington, and Jimenez (1999; but see Happe, 1994) reported that weak central coherence was associated with poor performance on theory of mind tasks in children with autism and in nonautistic children and adults. Thus, it might be argued that impaired temporal binding leads indirectly to impaired socialization and communication.

A problem with the theory of mind account of autism is that theory of mind does not normally develop until the age of about 4 years (Lewis \& Mitchell, 1994) whereas autism can be identified as early as 18 months. However, 18-month-old children with autism show deficits in joint attention (Baron-Cohen, Cox, Baird, Swettenham, Nightingale, Morgan, Drew, \& Charman, 1996), which is widely accepted as being a precursor to theory of mind (Baron-Cohen, 1995; Mundy \& Sigman, 1989). The causes of joint attention impairments in autism are unclear, but one possibility is that they result from more basic difficulties with disengaging and switching attention (see Leekam \& Moore, 2001; McEvoy et al., 1993). If, as we suggested earlier, temporal binding deficits lead to impaired attention switching, this indicates an alternative or additional way in which defective temporal binding might contribute to impaired socialization and communication in autism.

However, we do not believe that impaired temporal binding deficits can provide a complete account of these deficits. In particular, the impairments of affective responsivity and reciprocity, which are hallmarks of autism and can occur in the absence of other autismrelated impairments (Santangelo \& Folstein, 1999), in our view almost certainly stem from quite different underlying deficits. This theoretical position is consistent with genetic studies suggesting that autism is caused by the convergence of at least three or four interacting genes (Pickles, Bolton, MacDonald, Bailey, Le Couteur, Sim, \& Rutter, 1995) and evidence that individuals without autism can 
demonstrate a local processing bias (so-called field independence) in the absence of social and communication deficits (e.g., Witkin \& Goodenough, 1981).

\section{Concluding Remarks}

Over the past 30 years, much evidence has accumulated regarding the cognitive and neurological bases of autism. Challenges still facing research into autism lie first in relating the behavioral symptoms to corresponding deficits in brain systems (determining vertical relationships) and second in relating the set of apparently independent behavioral symptoms to each other (determining horizontal relationships; Robbins, 1997). The main aim of this paper has been to present a hypothesis concerning possible vertical links between the behavioral features of autism associated with weak central coherence and neural mechanisms involved in temporal binding. We have also briefly discussed possible horizontal links between weak central coherence, which is understood in terms of defective temporal binding, and some of the executive function impairments and impairments of social cognition that characterize autism.

The hypothesis that we have proposed can be viewed at three levels of increasing specificity. At the most abstract level, we have assumed that normal cognitive and neural development depends not only on the progressive specialization of brain regions but also on the integration of activity between specialized regions or modules. Our hypothesis is that in autism the process of integration is somehow impaired so that local specialized networks process information in increasing isolation. At a more specific level, we proposed that this breakdown in integration is caused by deficits in temporal binding between local networks, termed hypocoupling (cf. Nunez, 2000). Finally, we proposed that abnormalities of visual perception and language processing associated with weak central coherence may be understood in terms of reduced coherence of oscillatory activity in the gamma frequency band.

The major advantage of the hypothesis is that it is directly testable, and we have made several predictions regarding the outcome of potential neurophysiological studies of autism. By providing testable hypotheses, we hope to advance the understanding of the neural correlates of cognitive functioning in autism, even if these hypotheses are later proved wrong.

However, we add some notes of caution. In the first place, the temporal binding deficit hypothesis stands or falls on the validity of the theory that temporally coordinated high-frequency neural activity constitutes a solution to the binding problem. Although temporal binding is currently a "hot topic" in neuroscience, the concept of temporal binding is not without its critics. For example, Shadlen and Movshon (1999) have proposed that widely distributed groups of cells with highly specialized responses may allow pooling of information with no need to resort to a temporal code. They further argue that the temporal relationships involved in a temporal binding solution would not be sufficient to resolve the resultant complexity when many groups of neurons are concurrently active. Although there are theoretical ways in which this difficulty might be overcome (Basar, 1999; Nunez, 2000), questions remain concerning the adequacy of current theories involving temporal binding mechanisms.

In the second place, the evidence supporting the hypothesis that gamma synchronization is involved in solving the binding problem has also been criticized. For example, in direct recordings from animal cortex, Tovee and Rolls (1992) found little evidence of synchronized gamma activity when stimuli other than moving light bars were used. However, the adaptation of both measurement and analysis techniques in recent years has shown that cells in different cortical regions do fire in synchrony at a range of gamma frequencies in response to the same stimulus (Bressler, 1996; Friedman-Hill, Maldonado, \& Gray, 2000; Frien \& Eckhorn, 2000).

In sum, the temporal binding deficit hypothesis of autism reflects current views in the field of neuroscience but is dependent on advances in research in this area. There are many such advances ongoing in addition to those studies already mentioned (see, e.g., Basar, 1999; Basar et al., 2000, 2001; 
Klimesch, 1996). The temporal binding deficit hypothesis as presented here should therefore be viewed as a working hypothesis for investigating brain-behavior relationships in autism, rather than as a hypothesis that we expect to remain unaltered as empirical work proceeds in neural dynamics and in the study of autism.

\section{References}

American Psychiatric Association. (1994). Diagnostic and statistical manual of mental disorders (4th ed.). Washington, DC: Author.

Bailey, A., Phillips, W., \& Rutter, M. (1996). Autism: Towards an integration of clinical, genetic, neuropsychological, and neurobiological perspectives. Journal of Child Psychology and Psychiatry and Allied Disciplines, 37, 89-126.

Barlow, H. B. (1972). Single units and cognition: A neurone doctrine for perceptual psychology. Perception, 1, 371-394.

Baron-Cohen, S. (1995). Mindblindness: An essay on autism and theory of mind. Cambridge: MIT Press.

Baron-Cohen, S., Cox, A., Baird, G., Swettenham, J., Nightingale, N., Morgan, K., Drew, A., \& Charman, T. (1996). Psychological markers of autism at 18 months of age in a large population. British Journal of Psychiatry, 168, 158-163.

Baron-Cohen, S., Tager-Flusberg, H., \& Cohen, D. J. (Eds.). (2000). Understanding other minds: Perspectives from developmental cognitive neuroscience. Oxford: Oxford University Press.

Basar, E. (1999). Brain function and oscillations: II. Integrative brain function. Neuropsychology and cognitive processes. Berlin: Springer.

Basar, E., Basar-Eroglu, C., Karakas, A., \& Schürmann, M. (2000). Brain oscillations in perception and memory. International Journal of Psychophysiology, 35, 95-124.

Basar, E., Basar-Eroglu, C., Karakas, S., \& Schürmann, M. (2001). Gamma, alpha, delta, and theta oscillations govern cognitive processes. International Journal of Psychophysiology, 39, 241-248.

Bott, L., Brockdorff, N., Brock, J., Lamberts, K., \& Boucher, J. (2002). Perceptual similarity in autism. Manuscript in preparation.

Braeutigam, S., Bailey, A. J., \& Swithenby, S. J. (2001). Phase-locked gamma band responses to semantic violation stimuli. Cognitive Brain Research, 10, 365377.

Braitenberg, V. (1978). Cortical architectonics: General and areal. In M. E. B. Brazier \& H. Petsche (Eds.), Architectonics of the cerebral cortex (pp. 443-465). New York: Raven Press.

Bressler, S. L. (1996). Interareal synchronization in the visual cortex. Behavioural Brain Research, 76, 37-49.

Brian, J. A., \& Bryson, S. E. (1996). Disembedding performance and recognition memory in autism/PDD. Journal of Child Psychology and Psychiatry and Allied Disciplines, 37, 865-872.

Brown, C. C. (2001). Investigating the role of gamma EEG as a solution to the binding problem. Unpublished doctoral thesis, University of Bristol, Bristol, England.

Carey, S., \& Diamond, R. (1977). From piecemeal to configurational representation of faces. Science, 195, 312-314.
Ciesielski, K. T., \& Harris, R. J. (1997). Factors related to performance failure on executive tasks in autism. Child Neuropsychology, 3, 1-12.

Cohen, I. L. (1994). An artificial neural-network analog of learning in autism. Biological Psychiatry, 36, 5-20.

Connolly, J. F., Phillips, N. A., \& Forbes, K. A. K. (1995). The effects of phonological and semantic features of sentence ending words on visual event-related potentials. Electroencephalography and Clinical Neurophysiology, 94, 276-287.

Damasio, A. R., \& Maurer, R. G. (1978). A neurological model for childhood autism. Archives of Neurology, 35, 777-786.

Davies, S., Bishop, D., Manstead, A., \& Tantam, D. (1994). Face perception in autistic children. Journal of Child Psychology and Psychiatry and Allied Disciplines, 35, 1033-1058.

Dunn, M., Vaughan, H., Kreuzer, J., \& Kurtzberg, D. (1999). Electrophysiologic correlates of semantic classification in autistic and normal children. Developmental Neuropsychology, 16, 79-99.

Elman, J., Bates, E., Johnson, M., Karmiloff-Smith, A., Parisi, D., \& Plunkett, K. (1996). Rethinking innateness: A connectionist perspective on development. Cambridge: MIT Press.

Engel, A. K., König, P., Kreiter, A. K., Schillen, T. B., \& Singer, W. (1992). Temporal coding in the visual cortex: New vistas on integration in the nervous system. Trends in Neurosciences, 15, 218-226.

Eskes, G. A., Bryson, S. E., \& McCormick, T. A. (1990). Comprehension of concrete and abstract words in children with autism. Journal of Autism and Developmental Disorders, 20, 61-73.

Fost, J. W. (1999). Neural rhythmicity, feature binding, and serotonin: A hypothesis. Neuroscientist, 5, 7985.

Friedman-Hill, S., Maldonado, P. E., \& Gray, C. M. (2000). Dynamics of striate cortical activity in the alert macaque: 1. Incidence and stimulus-dependence of gamma-band neuronal oscillations. Cerebral Cortex, 10, 1105-1116.

Frien, A., \& Eckhorn, R. (2000). Functional coupling shows stronger stimulus dependence for fast oscillations than for low-frequency components in striate cortex of awake monkey. European Journal of Neuroscience, 12, 1466-1478.

Frith, U. (1989). Autism: Explaining the enigma. Oxford: Blackwell.

Frith, U. (1997). The neurocognitive basis of autism. Trends in Cognitive Sciences, 1, 73-77.

Frith, U., \& Happé, F. G. E. (1994). Autism-Beyond theory of mind. Cognition, 50, 115-132.

Frith, U., \& Snowling, M. (1983). Reading for meaning and reading for sound in autistic and dyslexic children. Journal of Developmental Psychology, 1, 329342.

Ghose, G. M., \& Maunsell, J. (1999). Specialized repre- 
sentations in visual cortex: A role for binding? $\mathrm{Neu}$ ron, 24, 79-85.

Gray, C. M. (1999). The temporal correlation hypothesis of visual feature integration: Still alive and well. $\mathrm{Neu}$ ron, 24, 31-47.

Gruber, T., Müller, M. M., Keil, A., \& Elbert, T. (1999a). Modulation of induced gamma band response in a perceptual learning task in human EEG. Psychophysiology, 36, S55.

Gruber, T., Müller, M. M., Keil, A., \& Elbert, T. (1999b). Selective visuo-spatial attention alters induced gamma band responses in the human EEG. Clinical Neurophysiology, 110, 2074-2085.

Gustafsson, L. (1997). Inadequate cortical feature maps: A neural circuit theory of autism. Biological Psychiatry, 42, 1138-1147.

Happé, F. G. E. (1994). Wechsler IQ profile and theory of mind in autism: A research note. Journal of Child Psychology and Psychiatry and Allied Disciplines, 35, 1461-1471.

Happé, F. G. E. (1996). Studying weak central coherence at low levels: Children with autism do not succumb to visual illusions. A research note. Journal of Child Psychology and Psychiatry and Allied Disciplines, 37, 873-877.

Happé, F. G. E. (1997). Central coherence and theory of mind in autism: Reading homographs in context. Brit ish Journal of Developmental Psychology, 15, 1-12.

Happé, F. G. E. (1999). Autism: Cognitive deficit or cognitive style? Trends in Cognitive Sciences, 3, 216222.

Harris, P. (1993). Pretending and planning. In S. BaronCohen, H. Tager-Flusberg, \& D. J. Cohen (Eds.), Understanding other minds: Perspectives from autism (pp. 228-246). Oxford: Oxford University Press.

Hillyard, S. A., \& Anllo-Vento, L. (1998). Event-related brain potentials in the study of visual selective attention. Proceedings of the National Academy of Science, USA, 95, 781-787.

Hobson, R. P. R. (1993). Autism and the development of mind. Hove, UK: Erlbaum.

Hubel, D. H., \& Weisel, T. N. (1977). Functional architecture of macaque monkey visual cortex. Proceedings of the Royal Society of London B, 198, 1-59.

Hubel, D. H., \& Wiesel, T. N. (1979). Brain mechanisms of vision. Scientific American, 241, 150-162.

Hughes, C., Russell, J., \& Robbins, T. W. (1994). Evidence for executive dysfunction in autism. Neuropsychologia, 32, 477-492.

Jarrold, C., Butler, D. W., Cottington, E. M., \& Jiminez, F. (2000). Linking theory of mind and central coherence bias in autism and in the general population. $D e$ velopmental Psychology, 36, 126-128.

Johnson, M. H. (1999). Cortical plasticity in normal and abnormal cognitive development: Evidence and working hypotheses. Development and Psychopathology, 11, 419-437.

Jolliffe, T., \& Baron-Cohen, S. (1997). Are people with autism and Asperger syndrome faster than normal on the embedded figures test? Journal of Child Psychology and Psychiatry and Allied Disciplines, 38, 527534.

Jolliffe, T., \& Baron-Cohen, S. (1999). A test of central coherence theory: Linguistic processing in high-functioning adults with autism or Asperger syndrome: Is local coherence impaired? Cognition, 71, 149-185

Klimesch, W. (1996). Memory processes, brain oscilla- tions and EEG synchronization. International Journal of Psychophysiology, 24, 61-100.

Klinger, L. G., \& Dawson, G. (in press). Prototype formation in autism. Development and Psychopathology.

Kohonen, T. (1984). Self-organizing and associative memory (3rd ed.). Berlin: Springer-Verlag.

Kohonen, T. (1995). Self-organizing maps. Berlin: Springer-Verlag.

Kutas, M., \& Federmeier, K. D. (2000). Electrophysiology reveals semantic memory use in language comprehension. Trends in Cognitive Sciences, 4, 463470 .

Kutas, M., \& Hillyard, S. A. (1980). Reading senseless sentences: Brain potentials reveal semantic incongruity. Science, 207, 203-205.

Langdell, T. (1978). Recognition of faces: An approach to the study of autism. Journal of Child Psychology and Psychiatry and Allied Disciplines, 19, 255-268.

Leekam, S., \& Moore, C. (2001). The development of attention and joint attention in children with autism. In J. Burack, T. Charman, N. Yirmiya, \& P. R. Zelazo (Eds.), The development of autism. Mahwah, NJ: Erlbaum.

Lewis, C., \& Mitchell, P. (1994). Children's early understanding of mind. Hove, UK: Erlbaum.

Love, B. C., Rouder, J. N., \& Wisniewski, E. J. (1999). A structural account of global and local processing. Cognitive Psychology, 38, 291-316.

McClelland, J. L. (2000). The basis of hyperspecificity in autism: A preliminary suggestion based on the properties of neural nets. Journal of Autism and Developmental Disorders, 30, 497-502.

McEvoy, R. E., Rogers, S. J., \& Pennington, B. F. (1993). Executive function and social communication deficits in young autistic children. Journal of Child Psychology and Psychiatry and Allied Disciplines, 34, 563578

Meltzoff, A., \& Gopnik, A. (1994). The role of imitation in understanding persons and developing a theory of mind. In S. Baron-Cohen \& H. Tager-Flusberg (Eds.), Understanding other minds: Perspectives from autism (pp. 335-366). Oxford: Oxford University Press.

Milner, P. M. (1974). A model for visual shape recognition. Psychological Review, 81, 521-535.

Minshew, N. J., Goldstein, G., \& Siegel, D. J. (1997). Neuropsychologic functioning in autism: Profile of a complex information processing disorder. Journal of the International Neuropsychological Society, 3, 303-316.

Minshew, N. J., Luna, B., \& Sweeney, J. A. (1999). Oculomotor evidence for neocortical systems but not cerebellar dysfunction in autism. Neurology, 52, 917922

Miyashita, T. (1988). Discrimination of facial components in autistic children. Japanese Journal of Psychology, 59, 206-212.

Molesworth, C. J., Bowler, D. M., \& Hampton, J. A (2002). The prototype effect in recognition memory: Intact in autism? Manuscript in preparation.

Mottron, L., \& Belleville, S. (1993). A study of perceptual analysis in a high level autistic subject with exceptional graphic abilities. Brain and Cognition, 23, 279-309.

Mottron, L., Belleville, S., \& Ménard, E. (1999). Local bias in autistic subjects as evidenced by graphic tasks: Perceptual hierarchization or working memory defi- 
cit? Journal of Child Psychology and Psychiatry and Allied Disciplines, 40, 743-755.

Mottron, L., Burack, J. A., Stauder, J. E. A., \& Robaey, P. (1999). Perceptual processing among high-functioning persons with autism. Journal of Child Psychology and Psychiatry and Allied Disciplines, 40, 203-211.

Müller, M. M., Bosch, J., Elbert, T., Kreiter, A., Sosa, M. V., Sosa, P. V., \& Rockstroh, B. (1996). Visually induced gamma-based responses in human electroencephalographic activity-A link to animal studies. Experimental Brain Research, 112, 96-102.

Müller, M. M., Junghofer, M., Elbert, T., \& Rockstroh, B. (1997). Visually induced gamma-band responses to coherent and incoherent motion: A replication study. NeuroReport, 8, 2575-2579.

Mundy, P., \& Sigman, M. (1989). The theoretical implications of joint-attention deficits in autism. Development and Psychopathology, 1, 173-183.

Navon, D. (1977). Forest before trees: The precedence of global features in visual perception. Cognitive Psychology, 9, 353-383.

Nunez, P. L. (1998). Neocortical dynamics of macroscopic-scale EEG measurements. IEEE Engineering in Medicine and Biology, 17, 110-117.

Nunez, P. L. (2000). Toward a quantitative description of large scale neocortical dynamic function and EEG. Behavioral and Brain Sciences, 23, 371-437.

O'Leary, D. D. M. (1989). Do cortical areas emerge from a protocortex? Trends in Neurosciences, 12, 400-406.

Oliver, A., Johnson, M. H., Karmiloff-Smith, A., \& Pennington, B. (2000). Deviations in the emergence of representations: A neuroconstructivist framework for analysing developmental disorders. Developmental Science, 3, 1-40.

O'Riordan, M. (2000). Superior modulation of activation levels of stimulus representations does not underlie superior discrimination in autism. Cognition, 77, 81-96.

O’Riordan, M. A., Plaisted, K. C., Driver, J., \& BaronCohen, S. (2001). Superior visual search in autism. Journal of Experimental Psychology: Human Perception and Performance, 27, 719-730.

Ozonoff, S. (1995). Executive functions in autism. In E. Schopler \& G. B. Mesibov (Eds.), Learning and cognition in autism (pp. 199-219). New York: Plenum Press.

Ozonoff, S. (1997). Components of executive function in autism and other disorders. In J. Russell (Ed.), Autism as an executive disorder (pp. 179-211). Oxford: Oxford University Press.

Ozonoff, S., \& Jensen, J. (1999). Brief report: Specific executive function profiles in three neurodevelopmental disorders. Journal of Autism and Developmental Disorders, 29, 171-177.

Ozonoff, S., \& Miller, J. N. (1996). An exploration of right-hemisphere contributions to the pragmatic impairments of autism. Brain and Language, 52, 411434.

Ozonoff, S., Pennington, B. F., \& Rogers, S. J. (1991). Executive function deficits in high-functioning autistic individuals-Relationship to theory of mind. Journal of Child Psychology and Psychiatry and Allied Disciplines, 32, 1081-1105.

Ozonoff, S., Strayer, D. L., McMahon, W. M., \& Filloux, F. (1994). Executive function abilities in autism and Tourette syndrome: An information processing ap- proach. Journal of Child Psychology and Psychiatry and Allied Disciplines, 35, 1105-1032.

Pennington, B. F. (1994). The working memory function of the prefrontal cortices: Implications for developmental and individual differences in cognition. In M. M. Haith, J. Benson, R. Roberts, \& B. F. Pennington (Eds.), Future-oriented processes in development (pp. 243-298). Chicago: University of Chicago Press.

Pickles, A., Bolton, P., MacDonald, H., Bailey, A., Le Couteur, A., Sim, C. H., \& Rutter, M. (1995). Latentclass analysis of recurrence risks for complex phenotypes with selection and measurement error: A twin and family history study of autism. American Journal of Human Genetics, 57, 717-726.

Plaisted, K. C. (2000). Aspects of autism that theory of mind cannot explain. In S. Baron-Cohen, H. TagerFlusberg, \& D. J. Cohen (Eds.), Understanding other minds: Perspectives from developmental cognitive neuroscience (pp. 222-250). Oxford: Oxford University Press.

Plaisted, K., O'Riordan, M., \& Baron-Cohen, S. (1998a). Enhanced discrimination of novel, highly similar stimuli by adults with autism during a perceptual learning task. Journal of Child Psychology and Psychiatry and Allied Disciplines, 39, 765-775.

Plaisted, K., O'Riordan, M., \& Baron-Cohen, S. (1998b). Enhanced visual search for a conjunctive target in autism: A research note. Journal of Child Psychology and Psychiatry and Allied Disciplines, 39, 777-783.

Plaisted, K., Swettenham, J., \& Rees, E. (1999). Children with autism show local precedence in a divided attention task and global precedence in a selective attention task. Journal of Child Psychology and Psychiatry and Allied Disciplines, 50, 733-742.

Prior, M. R., \& Hoffmann, W. (1990). Neuropsychological testing of autistic children through an exploration with frontal lobe tests. Journal of Autism and Developmental Disorders, 20, 581-590.

Pulvermüller, F., Lutzenberger, W., Preissl, H., \& Birbaumer, N. (1995). Spectral responses in the gammaband: Physiological signs of higher cognitive processes? NeuroReport, 6, 2059-2064.

Pulvermüller, F., Preissl, H., Lutzenberger, W., \& Birbaumer, N. (1996). Brain rhythms of language: Nouns versus verbs. European Journal of Neuroscience, 8, 937-941.

Riesenhuber, M., \& Poggio, T. (1999). Are cortical models really bound by the "binding problem"? Neuron, 24, 87-93.

Rinehart, N. J., Bradshaw, J. L., Moss, S. A., Brereton, A. V., \& Tonge, B. J. (2000). Atypical interference of local detail on global processing in high-functioning autism and Asperger's disorder. Journal of Child Psychology and Psychiatry and Allied Disciplines, 41, 769-778.

Robbins, T. W. (1997). Integrating the neurobiological and neuropsychological dimensions of autism. In J. Russell (Ed.), Autism as an executive disorder (pp. 21-53). Oxford: Oxford University Press.

Rodriguez, E., George, N., Lachaux, J., Martinerie, J., Renault, B., \& Varela, F. J. (1999). Perception's shadow: Long-distance synchronization of human brain activity. Nature, 397, 430-433.

Rogers, S. J., \& Pennington, B. F. (1991). A theoretical approach to the deficits in infantile autism. Development and Psychopathology, 3, 137-162.

Ropar, D., \& Mitchell, P. (1999). Are individuals with autism and Asperger's syndrome susceptible to visual 
illusions. Journal of Child Psychology and Psychiatry and Allied Disciplines, 40, 1283-1293.

Ropar, D., \& Mitchell, P. (2001). Susceptibility to illusions and performance on visuospatial tasks in individuals with autism. Journal of Child Psychology and Psychiatry and Allied Disciplines, 42, 539-549.

Rosenblatt, F. (1961). Principles of neurodynamics: Perception and the theory of brain mechanisms. Washington, DC: Spartan Books.

Rumsey, J. M., \& Hamburger, S. D. (1988). Neuropsychological findings in high-functioning autistic men with infantile autism, residual state. Journal of Clinical and Experimental Psychology, 10, 201-221.

Santangelo, S. L., \& Folstein, S. E. (1999). Autism: A genetic perspective. In H. Tager-Flusberg (Ed.), Neurodevelopmental disorders: Contributions to a new framework from the cognitive neurosciences (pp. 431-448). Boston: MIT Press.

Shadlen, M. N., \& Movshon, J. A. (1999). Synchrony unbound: A critical evaluation of the temporal binding hypothesis. Neuron, 24, 67-77.

Shah, A., \& Frith, U. (1983). An islet of ability in autistic-children-A research note. Journal of Child Psychology and Psychiatry and Allied Disciplines, 24, 613-620.

Shah, A., \& Frith, U. (1993). Why do autistic individuals show superior performance on the block design task? Journal of Child Psychology and Psychiatry and Allied Disciplines, 34, 1351-1364.

Shaw, J. C. (1981). An introduction to the coherence function and its use in EEG signal analysis. Journal of Medical Engineering and Technology, 5, 279-288.

Shaw, J. C. (1984). Correlation and coherence analysis of the EEG: A selective tutorial review. International Journal of Psychophysiology, 1, 255-266.

Singer, W. (1999a). Binding by neural synchrony. Cambridge: MIT Press.

Singer, W. (1999b). Neuronal synchrony: A versatile code for the definition of relations? Neuron, 24, 4965.

Singer, W., Engel, A. K., Kreiter, A. K., Munk, M. H. J., Neuenschwander, S., \& Roelfsema, P. R. (1997). Neuronal assemblies: Necessity, signature and detectability. Trends in Cognitive Sciences, 1, 252-261.

Smith, E. E., \& Jonides, J. (1999). Neuroscience-Storage and executive processes in the frontal lobes. Science, 283, 1657-1661.

Snowling, M., \& Frith, U. (1986). Comprehension in hyperlexic readers. Journal of Experimental Child Psychology, 42, 392-415.

Steinmetz, P. N., Roy, A., Fitzgerald, P. J., Hsiao, S. S., Johnson, K. O., \& Niebur, E. (2000). Attention modulates synchronized neuronal firing in primate somatosensory cortex. Nature, 404, 187-190.

Tallon-Baudry, C., \& Bertrand, O. (1999). Oscillatory gamma activity in humans and its role in object representation. Trends in Cognitive Sciences, 3, 151-162.

Tallon-Baudry, C., Bertrand, O., Delpeuch, C., \& Pernier, J. (1996). Stimulus specificity of phase-locked and non-phase-locked $40 \mathrm{~Hz}$ visual responses in humans. Journal of Neuroscience, 16, 4240-4249.

Tantam, D., Monaghan, L., Nicholson, H., \& Stirling, J. (1989). Autistic children's ability to interpret faces. Journal of Child Psychology and Psychiatry and Allied Disciplines, 30, 623-630.

Thatcher, R. W. (1992). Cyclic cortical reorganization during early-childhood. Brain and Cognition, 2, 24-50.

Thatcher, R. W. (1994a). Cyclic cortical reorganization: Origins of cognition. In G. Dawson \& K. Fischer (Eds.), Human behavior and the developing brain (pp. 232-268). New York: Guilford Press.

Thatcher, R. W. (1994b). Psychopathology of early frontal lobe damage: Dependence on cycles of development. Development and Psychopathology, 6, 565596.

Thatcher, R. W., Krause, P. J., \& Hrybyk, M. (1986). Cortico-cortical associations and EEG coherence: A two-compartmental model. Electroencephalography and Clinical Neurophysiology, 64, 123-143.

Tiitinen, H., Sinkkonen, J., Reinikainen, K., Alho, K., Lavikainen, J., \& Näätänen, R. (1993). Selective attention enhances the auditory $40-\mathrm{Hz}$ transient response in humans. Nature, 364, 59-60.

Tononi, G., Edelman, G. M., \& Sporns, O. (1998). Complexity and coherency: Integrating information in the brain. Trends in Cognitive Sciences, 2, 474-484.

Tovee, M. J., \& Rolls, E. T. (1992). Oscillatory activity is not evident in the primate temporal visual cortex with static stimuli. NeuroReport, 3, 369-372.

Treisman, A. (1998). Feature binding, attention and object perception. Philosophical Transactions of the Royal Society of London, B, 353, 1295-1306.

Treisman, A. (1999). Solutions to the binding problem: Progress through controversy and convergence. Neuron, 24, 105-110.

van Dalen, J. G. T. (1994). Autism: Seen from the inside Unpublished manuscript.

von der Malsburg, C. (1981). The correlation theory of brain function (Internal Report 81-2). Göttingen, Germany: Max-Planck-Institute for Biophysical Chemistry.

von der Malsburg, C. (1999). The what and why of binding: The modeler's perspective. Neuron, 24, 95-104.

Wing, L. (1996). The autistic spectrum: A guide for parents and professionals. London: Constable.

Witkin, H. A., \& Goodenough, D. R. (1981). Cognitive styles: Essence and origins. New York: International University Press.

World Health Organization (1992). International classification of diseases and disorders (10th ed.). Geneva, Switzerland: Author. 